\title{
Genetics of severe hypercholesterolemia in the general population: Insights from the STANISLAS cohort
}

\author{
Constance Xhaard ${ }^{1 *}$, João Pedro Ferreira1*, Edith Le Floch², Zohra Lamiral1', \\ Claire Dandine-Roulland ${ }^{2}$, Delphine Bacq-Daian², Erwan Bozec', Jean-Marc Boivin', \\ Nicolas Girerd', Jean-François Deleuze'2, Faiez Zannad', Patrick Rossignol'
}

'Université de Lorraine, INSERM, Centre d'Investigations Cliniques Plurithématique 1433, INSERM 1116, CHRU de Nancy, FCRIN INI-CRCT, Nancy, France

${ }^{2}$ Centre National de Recherche en Génomique Humaine, Institut François Jacob, CEA, Université Paris-Saclay, Evry, France ${ }^{*}$ Co-first authors

\section{ABSTRACT}

Background: Severe hypercholesterolemia $(\mathrm{SH})$ is a common condition characterized by increased levels of total and low-density lipoprotein cholesterol (LDLC). Methods: The aim of this study is to screen for prevalence of hypercholesterolemia, perform heritability estimation of circulating lipoproteins and study the association between SH cases and surrogate cardiovascular disease markers among participants of STANISLAS cohort. Gene candidate analyses were utilized to investigate the association between lipid levels, $\mathrm{SH}$ and polymorphisms from the three commonly reported genes ( $A P O B, L D L R$ and PCSK9). Results: Participants with $\mathrm{SH}(\mathrm{n}=102 ; 6.9 \%)$ were older ( $58 \mathrm{vs.} 51 \mathrm{yr}$ ), had higher total cholesterol ( $290 \mathrm{vs.} 209 \mathrm{mg} / \mathrm{dL}), \mathrm{LDLc}(206 \mathrm{vs.} 136 \mathrm{mg} / \mathrm{dL}$ ) and triglycerides (114 vs. $88 \mathrm{mg} / \mathrm{dL}$ ). Despite smoking less, they had carotid plaques more frequently (21.2 vs. 9.3\%), higher cIMT (676 vs. $597 \mu \mathrm{m})$, and had more frequent family history cardiovascular disease. The circulating lipid levels have an important heritability: LDLc 51.6\%, HDLc 66.6\%, total cholesterol 49.8\%, and triglycerides $41.4 \%$. The SNPs located in LDLR gene present the strongest association with LDLc levels: rs55997232, rs17242395, rs1010679, and rs11668477. Conclusion: In a healthy cohort, participants with SH had premature vascular damage. LDLc had an important component of heritability and SNPs linked to the $L D L R$ gene presented a strong association with LDLc. These findings reinforce the need for an early identification and treatment of SH subjects, which is mostly polygenic.

KEY WORDS: Severe hypercholesterolemia, LDL cholesterol, heritability, genetic, arterial stiffness, target organ damage

\section{Corresponding author:}

Pr Patrick Rossignol

Centre d'Investigation Clinique 1433 module

Plurithématique, CHRU Nancy - Hopitaux de Brabois

Institut Lorrain du Coeur et des Vaisseaux Louis Mathieu

4 rue du Morvan, 54500 Vandoeuvre les Nancy

Tel.: +33 3831573 15, Fax : +33 383157324

E-mail: p.rossignol@chru-nancy.fr
ABBREVIATIONS: SH: Severe Hypercholesterolemia; LDLC: Low Density Lipoprotein cholesterol; HDLc: High density lipoprotein cholesterol; PWV: pulse-wave velocity; cIMT: carotid intima-media thickness; GRM: genetic relatedness matrix

Submission: 25.08.2021, Acceptance: 31.10 .2021 


\section{INTRODUCTION}

Hypercholesterolemia is a common but underdiagnosed condition characterized by increased levels of total and low-density lipoprotein cholesterol (LDLC). If left untreated, it may lead to premature cardiovascular events and death ${ }^{1,2,3}$. Two kinds of hypercholesterolemia have been reported, the familial form (Familial Hypercholesterolemia $\mathrm{FH}$ ) and the sporadic form. The estimated prevalence of $\mathrm{FH}$ is $0.4 \%$ ( 1 person per 250 people) but the true worldwide prevalence of hypercholesterolemia is unknown because most patients remain undiagnosed ${ }^{4,5}$.

Familial hypercholesterolemia is defined by several criteria (Supplemental Table 1) including genetic mutations in low-density lipoprotein receptor $(L D L R)$, apolipoprotein $\mathrm{B}(A P O B)$ and proprotein convertase subtilisin/kexin type 9 (PCSK9) genes ${ }^{6,7}$. However, beyond the "monogenic causes" responsible of $\mathrm{FH}$, many people with hypercholesterolemia may present a polygenic severe form of hypercholesterolemia ( $\mathrm{SH}$, severe Hypercholesterolemia). Many of these polygenic forms remain to be characterized ${ }^{8}$.

The STANISLAS (Suivi Temporaire Annuel Non-Invasif de la Santé des Lorrains Assurés Sociaux) cohort is a singlecentre familial longitudinal cohort from the Lorraine region of France, where the circulating levels of cholesterol and triglycerides were determined along with a detailed cardiovascular phenotyping ${ }^{9}$. Importantly, the familial design of this cohort allows the estimation of heritability of many variables including circulating lipoproteins.

The objectives of this study are to: 1) screen for prevalence of hypercholesterolemia among the participants, 2) describe the characteristics of the participants with hypercholesterolemia , 3) perform heritability estimation of circulating lipoproteins, 4) assess for potential familial form of hypercholesterolemia accordingly to genetic characteristics, and 5) study the association between $\mathrm{SH}$ cases and surrogate cardiovascular disease markers.

\section{METHODS}

\section{Study population}

The design of the STANISLAS cohort has been previously published ${ }^{9}$. In brief, the STANISLAS cohort is a singlecenter familial longitudinal cohort composed of 1,006 families (4,295 subjects) from the Nancy region recruited in 1993-1995 at the Center for Preventive Medicine. The cohort was established with the primary objective of investigating gene-gene and gene-environment interactions in the field of cardiovascular diseases. The study protocols for all examinations were reviewed and approved by the local Ethic Committee of CPP Est 3, France. All participants provided written informed consent to participate in the study. The most recent visit (fourth visit, V4) included 1705 subjects. For the present analysis, we excluded 213 subjects that were treated with a statin, and 17 participants who had missing LDLc values. The study population included a total of 1475 subjects, among whom, 1377 were successfully genotyped (Figure 1 ).

\section{Study design}

All participants were observed at the Centre $d^{\prime}$ Investigation Clinique Plurithématique Pierre Drouin at the University Center Hospital of Nancy (CIC-P de Nancy). Samples were collected early morning after an overnight fasting period. Standardized sample handling procedures enabled the collection of serum and plasma. Blood lipids were determined after plasma centrifugation in the central

SUPPLEMENTAL TABLE 1. Comparison of diagnostic criteria for the FH (from McGowan et al, 2019)

\begin{tabular}{|c|c|c|c|c|c|}
\hline Criteria & MedPed & Dutch & Simon Broome & NLA & $\mathrm{AHA}$ \\
\hline Family history of premature CAD & & + & + & + & + \\
\hline Family history of tendon Xanthomonas & & + & + & & \\
\hline Family history of hypercholesterolemia & + & + & + & + & \\
\hline Patient premature CAD & & + & & + & \\
\hline Patient premature PVD & & + & & & \\
\hline Tendon Xanthomonas & & + & + & + & \\
\hline Corneal arctus & & + & & + & \\
\hline Elevated LDLc & + & + & + & + & + \\
\hline Genetic mutation & & + & + & + & + \\
\hline
\end{tabular}

AHA: American heart Association, CAD: coronary artery disease, FH: familial hypercholesterolemia, LDLc: low density lipoprotein cholesterol, MedPed: make early diagnosis to prevent early death, NLA: National lipid association, PVD: peripheral vascular disease 


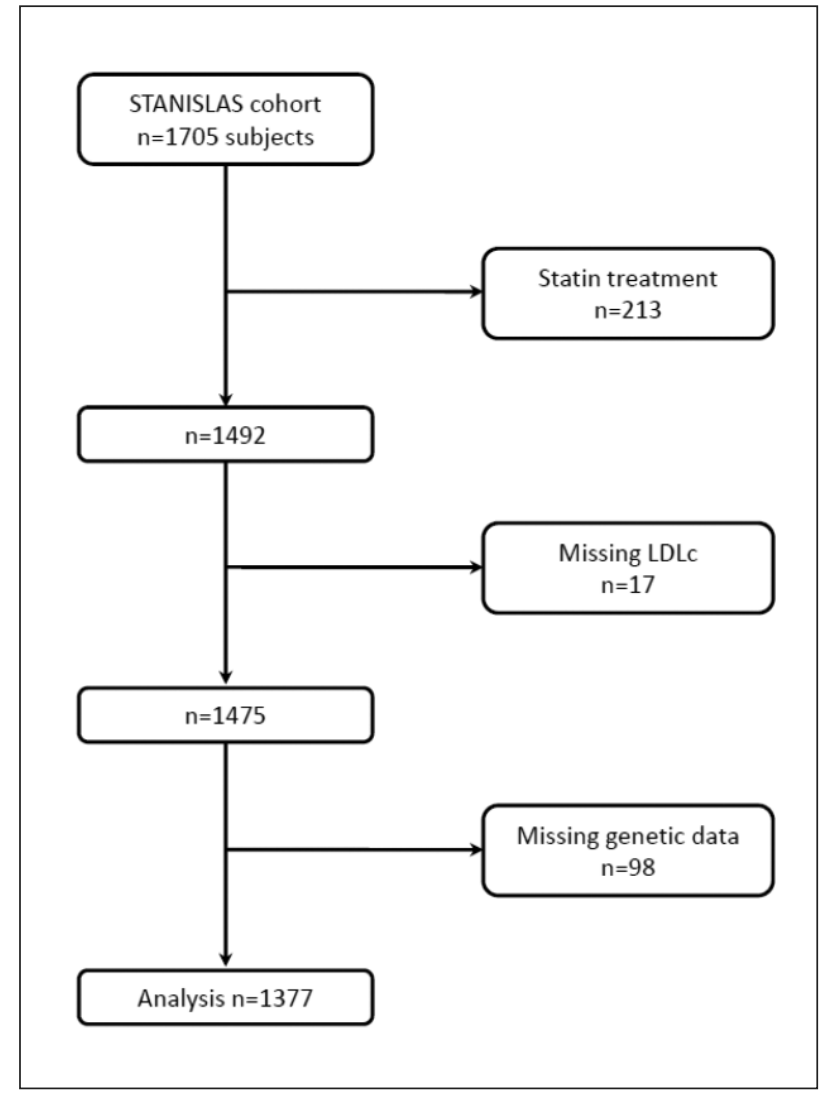

FIGURE 1. Study flow chart.

laboratory of the hospital using the Roche Cobas ${ }^{\circledR}$ lipid panel. LDL cholesterol levels were automatically calculated in the central laboratory using the Friedwald formula, excluding subjects with triglyceride levels superior to $4 \mathrm{~g} / \mathrm{L}$ in whom LDLc was not calculated. Personal and familial medical history, medications, anthropometric parameters, blood pressure, pulse-wave velocity (PWV), carotid intima-media thickness (CIMT) and echography (including carotid plaque assessment and echocardiography) were recorded ${ }^{10-12}$. Participants more likely to have any form of $\mathrm{SH}$ were identified on the basis of LDLC levels: $L D L c \geq 190 \mathrm{mg} / \mathrm{dL}$ if age $\geq 20 \mathrm{yr}$ and $L D L c \geq 160 \mathrm{mg} /$ $\mathrm{dL}$ if age $<20 \mathrm{yr}^{13,14}$.

\section{Genetic analyses and heritability estimations}

Blood DNA was extracted using Gentra Puregene Blood Kit (Qiagen, Hilden Germany ${ }^{\circledR}$ ) and stored at $-20^{\circ} \mathrm{C}$. Genotyping was conducted at the Centre National de Recherche en Génomique Humaine (CNRGH, Evry, France) using two chips: 1) the Illumina Global Screening Array (GSA) which is composed of 687572 intronic and exonic markers, and 2) the Illumina Exome Array, which is constituted of 244330 SNPs, mostly exonic.

For heritability estimation, we used a linear mixed model, which allowed to simultaneously include additive genetic effects across the genome, common environment effects shared by nuclear family and fixed effects (sex and age). The additive genetic effects were assessed using the Genetic Relatedness Matrix (GRM) which has been computed using polymorphic SNPs of included subjects and which is based on genotype correlations. The use of the GRM allowed a better inference of relatedness between siblings, instead of an expected average ${ }^{15}$.

Gene candidate association analyses were utilized in order to investigate the association between lipid levels, $\mathrm{SH}$ and genetic polymorphisms from the three commonly reported genes (APOB, LDLR and PCSK9). For each gene, we defined an interval that encompassed their boundaries ( $\pm 20 \mathrm{~kb}$ ) based on the reference genome built 37 from the Ensembl database (http://grch37.ensembl.org). Then we selected the SNPs from the two chips and performed usual quality control steps (Supplemental Table 2). A total of 7 SNPs were excluded for monomorphism, no SNP had $>5 \%$ of missing data and no SNP deviated from the Hardy-Weinberg equilibrium at a threshold of $p<1.10-8$. Then 29 other SNPs were excluded because they were on linkage disequilibrium $\left(r^{2}<0.9\right)$

Genetic analyses were performed using linear mixedeffect model in order to take into account pedigree data, under an additive genetic model (with age and sex as covariates). Results were considered statistically significant at $p<0.05$ after correction for multiple testing with a $1 \%$ false discovery rate. These analyses were performed with R (version 3.5.0) using the R package Gaston (gaston:

SUPPLEMENTAL TABLE 2. Selection and characteristics of SNP included in the study

\begin{tabular}{|c|c|c|c|c|c|c|c|c|c|c|}
\hline \multirow[b]{2}{*}{ Gene } & \multirow[b]{2}{*}{ Chromosome } & \multirow[b]{2}{*}{ Range } & \multirow{2}{*}{$\begin{array}{l}\text { SNP GSA } \\
\text { chip }\end{array}$} & \multirow{2}{*}{$\begin{array}{l}\text { SNP Exom } \\
\text { chip }\end{array}$} & \multicolumn{5}{|c|}{ Exclusion criteria } & \multirow{2}{*}{$\begin{array}{c}\text { SNP } \\
\text { included }\end{array}$} \\
\hline & & & & & Common & Monom. & $\begin{array}{l}\text { Callrate } \\
(<0.95)\end{array}$ & $\begin{array}{l}\text { HWeq } \\
\left(P>10^{-8}\right)\end{array}$ & $\begin{array}{c}\text { LD } \\
\left(r^{2}<0.9\right)\end{array}$ & \\
\hline PCSK9 & 1 & $55485221-55550525$ & 24 & 12 & 3 & 2 & 0 & 0 & 3 & 28 \\
\hline$L D L R$ & 19 & $11180138-11264496$ & 43 & 8 & 6 & 3 & 0 & 0 & 14 & 28 \\
\hline$A P O B$ & 2 & $21204301-21286945$ & 43 & 47 & 23 & 2 & 0 & 0 & 12 & 53 \\
\hline
\end{tabular}

Monom.: monomoprphic; HWeq: hardy-Weinberg equilibrium; LD: linkage disequilibrium 
Genetic Data Handling \& Linear Mixed Models) for heritability estimation and GWAS analysis.

\section{Statistical analyses}

Continuous variables are expressed as means \pm standard deviation (SD) or median (interquartile range), categorical variables as frequencies (percentages), and odd ratios (ORs) as the point estimate and the respective $95 \%$ confidence interval $(95 \% \mathrm{Cl})$. Comparisons of characteristics were performed using Student's $t$-test or
Wilcoxon non parametric tests for continuous variables and $\mathrm{X}^{2}$ or exact Fisher tests for categorical variables. Factors associated with $\mathrm{SH}$ were assessed using both univariate and multivariate logistic regression with $\mathrm{SH}$ as binary outcome variable. First, univariate logistic regression was performed between $\mathrm{SH}$ and each variable significantly associated with SH with a $p<0.01$ in Table 1. Second, multivariable logistic regression was performed using a stepwise forward selection process, retaining only the variables associated with $\mathrm{SH}$ with a $p<0.05$ in

TABLE 1. Characteristics of the participants in the overall population and according to SH status

\begin{tabular}{|c|c|c|c|c|}
\hline Characteristic & $\begin{array}{l}\text { Overall } \\
(n=1475)\end{array}$ & $\begin{array}{l}\text { Unlikely SH } \\
(n=1373)\end{array}$ & $\begin{array}{c}\text { Possible SH } \\
(n=102)\end{array}$ & P-value* \\
\hline Age (years) & $53(33-59)$ & $51(33-59)$ & $58(50-61)$ & $<0.0001$ \\
\hline Male sex & $692(46.7 \%)$ & $646(46.8 \%)$ & 46 (45.1\%) & 0.76 \\
\hline Current smoker & $327(22.1 \%)$ & $313(22.7 \%)$ & $14(13.9 \%)$ & 0.046 \\
\hline BMI $\left(\mathrm{Kg} / \mathrm{m}^{2}\right)$ & $25(22-28)$ & $25(22-28)$ & $26(24-28)$ & 0.008 \\
\hline Diabetes & $45(3.1 \%)$ & $43(3.2 \%)$ & $2(2.0 \%)$ & 0.76 \\
\hline Glycated hemoglobin (\%) & $5.5(5.3-5.8)$ & $5.5(5.3-5.8)$ & $5.7(5.5-5.9)$ & $<0.0001$ \\
\hline Hypertension history & $233(15.8 \%)$ & 209 (15.2\%) & $24(23.8 \%)$ & 0.033 \\
\hline Mean 24h SBP (mmHg) & $119(113-126)$ & $119(113-126)$ & $120(114-127)$ & 0.36 \\
\hline Mean 24h DBP (mmHg) & $74 \pm 7$ & $74 \pm 7$ & $74 \pm 8$ & 0.84 \\
\hline Heart rate (bpm) & $63(57-69)$ & $63(57-69)$ & $62(58-68)$ & 0.51 \\
\hline eGFR $\left(\mathrm{ml} / \mathrm{min} / 1.73 \mathrm{~m}^{2}\right)$ & $98(88-110)$ & $98(88-110)$ & $94(85-100)$ & 0.0005 \\
\hline Microalbuminuria (mg/L) & $6.0(3.5-9.7)$ & $6.0(3.5-9.8)$ & $6.0(3.6-9.0)$ & 0.68 \\
\hline C-reactive protein (mg/L) & $1.4(0.7-3.2)$ & $1.4(0.7-3.2)$ & $1.5(0.8-2.2)$ & 0.49 \\
\hline Total cholesterol (mg/dL) & $215 \pm 39$ & $209 \pm 35$ & $290 \pm 18$ & $<0.0001$ \\
\hline $\mathrm{HDLc}(\mathrm{mg} / \mathrm{dL})$ & $58 \pm 14$ & $58 \pm 14$ & $60 \pm 13$ & 0.15 \\
\hline LDLc (mg/dL) & $136 \pm 34$ & $131 \pm 29$ & $206 \pm 13$ & $<0.0001$ \\
\hline Triglycerides (mg/dL) & $88(65-122)$ & $86(64-119)$ & $114(88-137)$ & $<0.0001$ \\
\hline IMT $(\mu \mathrm{m})$ & $600(512-703)$ & $597(510-694)$ & $676(560-778)$ & $<0.0001$ \\
\hline PWV (m/s) & $8.0(7.2-9.1)$ & $8.0(7.2-9.1)$ & $8.1(7.5-9.2)$ & 0.014 \\
\hline Carotid plaque & $146(10.1 \%)$ & $125(9.3 \%)$ & $21(21.2 \%)$ & 0.0007 \\
\hline CVD history & 150 (10.2 \%) & 140 (10.2 \%) & 10 (9.9\%) & 1.00 \\
\hline \multicolumn{5}{|l|}{ Family history of: } \\
\hline Myocardial infarction & 226 (15.4 \%) & 199 (14.6 \%) & 27 (26.5 \%) & 0.003 \\
\hline Stroke & $247(16.8 \%)$ & 218 (16.0 \%) & $29(28.4 \%)$ & 0.002 \\
\hline Hyperlipidemia & 603 (48.2 \%) & 544 (46.9 \%) & 59 (66.3\%) & 0.0004 \\
\hline
\end{tabular}

Legend: SH, Severe Hypercholesterolemia; BMI, body mass index; HDLc, high-density lipoprotein cholesterol; LDLc, low-density lipoprotein cholesterol; CVD, cardiovascular disease including any of myocardial infarction, stroke or peripheral artery disease; SBP, systolic blood pressure; DBP, diastolic blood pressure; IMT, intima-media thickness; PWV, pulse-wave velocity; eGFR, estimated glomerular filtration rate.

*Comparisons of characteristics were performed using Student's $t$-test or Wilcoxon non parametric tests for continuous variables and $x^{2}$ or exact Fisher tests for categorical variables 
the multivariable model. Assumptions of log linearity for continuous variables were checked using restricted cubic spline analyses. When log linearity hypothesis was not respected, continuous variables were categorized according to the shape of the spline curve. Accordingly, triglycerides, glycated hemoglobin and body mass index were expressed as binary covariates ( $\leq \mathrm{vs}$. $>88 \mathrm{mg} / \mathrm{dL}, \leq \mathrm{vs}$. $>5.5 \%$ and $\leq$ vs. $>25 \mathrm{~kg} / \mathrm{m}^{2}$, respectively). These analyses were performed using SAS version 9.4.6 (SAS Institute Inc., Cary, NC, USA) and the R software (version 3.5.0). A two-tailed significance level $p<0.05$ was used.

\section{RESULTS}

\section{Characteristics of the study population}

The comparison of the population characteristics by $\mathrm{SH}$ status is depicted in the Table 1. Participants with possible $\mathrm{SH}(\mathrm{n}=102 ; 6.9 \%)$ were older (58 vs. $51 \mathrm{yr}$ ), had higher total cholesterol (290 vs. $209 \mathrm{mg} / \mathrm{dL}$ ), LDL cholesterol (206 vs. $136 \mathrm{mg} / \mathrm{dL}$ ) and triglycerides (114 vs. $88 \mathrm{mg} / \mathrm{dL}$ ), higher glycated hemoglobin (5.7 vs. $5.5 \%$ ), had higher BMI (26 vs. $25 \mathrm{~kg} / \mathrm{m}^{2}$ ), had more often hypertension (23.8 vs. $15.2 \%$ ), had lower eGFR (94 vs.98 mL/min/1.73 $\mathrm{m}^{2}$ ), had carotid plaques more often (21.2 vs. 9.3\%), higher cIMT (676 vs. $597 \mu \mathrm{m})$, and higher PWV ( 8.1 vs $8.0 \mathrm{~m} / \mathrm{s}$ ) despite smoking less (13.9 vs. $22.7 \%$ ), and had more frequent family history of myocardial infarction (26.5 vs. $14.6 \%$ ), stroke (28.4 vs. $16.0 \%$ ), and hyperlipidemia (66.3 vs. $46.9 \%$ ) ( $p<0.05$ for all). The HDLc levels did not differ between groups. Table
1. In the multivariable logistic model higher cIMT, glycated hemoglobin and triglyceride levels, and family history of hyperlipemia remained independently associated with SH. Supplemental Table 3.

\section{Heritability estimations}

The circulating lipid levels have an important heritability component: LDLc 51.6\%, HDLc 66.6\%, total cholesterol $49.8 \%$, and triglycerides $41.4 \%$. The variance in the lipid levels explained by environmental factors shared by nuclear family was low, especially for LDL and total cholesterol: LDLc 3.9\%, HDLc 14.7\%, total cholesterol 4.8\%, and triglycerides $13.1 \%$. About $45 \%$ of the variance of LDLc, triglycerides and total cholesterol levels remain unexplained neither by genetic nor by common environment effects, except for HDLc for which unexplained variance represent only $18.7 \%$. Table 2 .

\section{Gene candidate analyses}

Gene candidate analysis for the 3 genes implicated in definition of familial form of hypercholesterolemia is shown in the Table 3. All allele frequencies are in concordance with those from European population panels of reference. Compared with the APOB and PCSK9 SNPs, those located in $L D L R$ gene present the strongest association with LDLc levels. After correction for test multiplicity, the LDLR SNPs rs55997232, rs17242395, rs1010679, and rs11668477, and the APOB SNPs rs1367117, rs6548010, rs6754295, rs481069, and rs61743299, remained associ-

SUPPLEMENTAL TABLE 3. Logistic regression (stepwise forward) of all factors in Table 1 with a $p<0.05$ to study those independently associated with possible $\mathrm{SH}$

\begin{tabular}{|c|c|c|c|c|}
\hline \multirow{2}{*}{ Characteristic } & \multicolumn{2}{|c|}{ Univariable } & \multicolumn{2}{|c|}{ Multivariable } \\
\hline & OR (95\%Cl) & P-value & OR $(95 \% \mathrm{Cl})$ & P-value \\
\hline Age (per year) & $1.04(1.02-1.06)$ & $<0.0001$ & & \\
\hline Current smoker & $0.55(0.31-0.97)$ & 0.041 & & \\
\hline Carotid plaques & $2.64(1.58-4.42)$ & 0.0002 & & \\
\hline BMI (per Kg/m²) & $1.51(1.01-2.27)$ & 0.047 & & \\
\hline Hypertension history & $1.74(1.07-2.81)$ & 0.024 & & \\
\hline IMT (per $10 \mu \mathrm{m}$ ) & $1.03(1.02-1.04)$ & $<0.0001$ & $1.02(1.01-1.04)$ & 0.002 \\
\hline PWV (per m/s) & $1.14(1.02-1.27)$ & 0.024 & & \\
\hline Glycated hemoglobin (>5.5\%) & $2.51(1.63-3.87)$ & $<0.0001$ & $2.04(1.25-3.34)$ & 0.004 \\
\hline Triglycerides (>88mg/dL) & $3.09(1.96-4.86)$ & $<0.0001$ & $2.60(1.57-4.29)$ & 0.0002 \\
\hline \multicolumn{5}{|l|}{ Family history of: } \\
\hline Myocardial infarction & $2.10(1.32-3.35)$ & 0.002 & & \\
\hline Stroke & $2.09(1.33-3.29)$ & 0.001 & & \\
\hline Hyperlipidaemia & $2.23(1.42-3.51)$ & 0.0005 & $2.01(1.25-3.21)$ & 0.0037 \\
\hline
\end{tabular}

Legend: SH, Severe hypercholesterolemia; BMI, body mass index; IMT, intima-media thickness; PWV, pulse-wave velocity. 
TABLE 2. Variance decomposition and heritability estimations

\begin{tabular}{lccc}
\hline Blood lipids & Heritability (\%) & Common environment effect (\%) & Residual effects (\%) \\
\hline LDL cholesterol & 51.6 & 3.9 & 44.4 \\
HDL cholesterol & 66.6 & 14.7 & 18.7 \\
Total cholesterol & 49.8 & 4.8 & 45.4 \\
Triglycerides & 41.4 & 13.1 & 45.5 \\
\hline
\end{tabular}

Legend: HDL, high-density lipoprotein; LDL, low-density lipoprotein.

Sex and age are used as covariates

TABLE 3. Association between SNP from the 3 gene candidates, the LDLc levels and SH

\begin{tabular}{|c|c|c|c|c|c|c|c|c|c|c|c|c|}
\hline \multirow[b]{2}{*}{ Gene } & \multirow[b]{2}{*}{ ID } & \multirow[b]{2}{*}{ Chr. } & \multirow[b]{2}{*}{ Position } & \multirow[b]{2}{*}{$\mathrm{A} 1$} & \multirow[b]{2}{*}{$A 2$} & \multirow[b]{2}{*}{ Freq. A2 } & \multirow[b]{2}{*}{ Beta } & \multirow[b]{2}{*}{ SD } & \multicolumn{2}{|c|}{$\begin{array}{l}\text { Association with } \\
\text { LDLc levels }\end{array}$} & \multicolumn{2}{|c|}{$\begin{array}{l}\text { Association } \\
\text { with SH }\end{array}$} \\
\hline & & & & & & & & & P-value & P BH & $\mathrm{P}$-value & $\mathrm{PBH}$ \\
\hline \multirow[t]{6}{*}{$L D L R$} & rs55997232 & 19 & 11188117 & $\mathrm{~T}$ & $\mathrm{C}$ & 0.867 & 0.090 & 0.018 & $9 \mathrm{E}-07$ & $3 \mathrm{E}-5$ & 0.019 & 0.28 \\
\hline & rs17242395 & 19 & 11206969 & A & G & 0.871 & 0.087 & 0.019 & $3 \mathrm{E}-06$ & $4.3 \mathrm{E}-5$ & 0.034 & 0.28 \\
\hline & rs1010679 & 19 & 11207102 & $\mathrm{C}$ & $\mathrm{T}$ & 0.780 & 0.062 & 0.015 & 4E-05 & $3.4 \mathrm{E}-4$ & 0.047 & 0.28 \\
\hline & rs11668477 & 19 & 11195030 & G & A & 0.785 & 0.062 & 0.015 & $5 E-5$ & $3.4 \mathrm{E}-4$ & 0.039 & 0.28 \\
\hline & rs 17243011 & 19 & 11242215 & A & G & 0.996 & 0.203 & 0.097 & 0.037 & 0.21 & NS & \\
\hline & rs72658879 & 19 & 11244008 & A & G & 0.959 & & & NS & & 0.049 & 0.28 \\
\hline \multirow[t]{8}{*}{ PCSK9 } & rs540796 & 1 & 55524197 & $A$ & G & 0.834 & 0.051 & 0.017 & 0.002 & 0.06 & 0.002 & 0.06 \\
\hline & rs505151 & 1 & 55529187 & G & A & 0.967 & -0.090 & 0.035 & 0.011 & 0.15 & NS & \\
\hline & rs11591147 & 1 & 55505647 & $\mathrm{~T}$ & G & 0.984 & 0.103 & 0.049 & 0.035 & 0.20 & NS & \\
\hline & rs2479394 & 1 & 55486064 & G & A & 0.707 & -0.028 & 0.014 & 0.036 & 0.20 & NS & \\
\hline & rs7552841 & 1 & 55518752 & $\mathrm{~T}$ & $C$ & 0.610 & -0.026 & 0.013 & 0.041 & 0.20 & 0.035 & 0.20 \\
\hline & rs28362277 & 1 & 55527222 & $C$ & A & 0.999 & & & NS & & 0.012 & 0.15 \\
\hline & rs487230 & 1 & 55541174 & $A$ & G & 0.783 & & & NS & & 0.036 & 0.20 \\
\hline & rs 28362263 & 1 & 55523855 & A & G & 0.999 & & & NS & & 0.041 & 0.20 \\
\hline \multirow[t]{11}{*}{$A P O B$} & rs1367117 & 2 & 21263900 & A & G & 0.690 & -0.045 & 0.013 & 0.0007 & 0.04 & 0.017 & 0.45 \\
\hline & rs6548010 & 2 & 21277922 & G & A & 0.683 & -0.042 & 0.013 & 0.002 & 0.05 & 0.048 & 0.51 \\
\hline & rs6754295 & 2 & 21206183 & G & $\mathrm{T}$ & 0.759 & 0.044 & 0.015 & 0.003 & 0.05 & NS & \\
\hline & rs481069 & 2 & 21281856 & G & A & 0.838 & 0.050 & 0.017 & 0.004 & 0.05 & NS & \\
\hline & rs61743299 & 2 & 21225597 & $\mathrm{~T}$ & A & 0.999 & -0.521 & 0.185 & 0.004 & 0.05 & 0.034 & 0.45 \\
\hline & rs515135 & 2 & 21286057 & $\mathrm{~T}$ & $C$ & 0.790 & 0.042 & 0.015 & 0.006 & 0.06 & NS & \\
\hline & rs1801695 & 2 & 21224853 & $\mathrm{~T}$ & $C$ & 0.968 & 0.098 & 0.037 & 0.008 & 0.06 & NS & \\
\hline & rs1042034 & 2 & 21225281 & $C$ & $\mathrm{~T}$ & 0.783 & 0.038 & 0.015 & 0.013 & 0.09 & NS & \\
\hline & rs12720796 & 2 & 21261998 & $\mathrm{C}$ & A & 0.979 & -0.086 & 0.043 & 0.046 & 0.27 & NS & \\
\hline & rs1801701 & 2 & 21228827 & $\mathrm{~T}$ & $C$ & 0.911 & & & NS & & 0.024 & 0.45 \\
\hline & rs1042023 & 2 & 21229446 & C & G & 0.983 & & & NS & & 0.033 & 0.45 \\
\hline
\end{tabular}

Legend: SH, severe hypercholesterolemia; LDLc, low-density lipoprotein cholesterol; Chr., chromosome; A1, allele 1; A2, allele 2; beta, effect per A2 under additive genetic model; SD, standard deviation; $\mathrm{BH}$, Benjamini-Hochberg corrected p-value; NS, association non-significant. Sex and age are used as covariates 
ated with LDLc. No SNPs located on PSCK9 gene reach the significant threshold after correction for test multiplicity. Table 3. Several LDLR, PCSK9, and APOB SNPs were associated with $\mathrm{SH}$, but none remained significant after correction for test multiplicity, they are almost the same than those associated with LDLc levels. Table 3. We did not find monogenic mutations of familial hypercholesterolemia, but all subjects with $\mathrm{SH}$ showed at least one mutated polymorphism from one of the 3 genes of interest.

Sensitive analysis are shown in Supplemental Table 4, where analyses without subjects that were not fasting $(n=30)$ have been run, results are similar than those in the Table 3, and in Supplemental Table 5, association tests between subjects taking statin or not taking statin for the 3 candidate genes implicated in familial form of hypercholesterolemia occurrence are shown, we find some polymorphisms in $A P O B$ gene linked with taking statin. However, results for association with LDL levels are similar with or without taking into account subjects with statin treatment (data not shown).

\section{DISCUSSION}

The present study shows that in a generally healthy populational cohort not taking statins, the proportion of participants with possible polygenic hypercholesterolemia was nearly 7\%; these participants had more frequently a family history of cardiovascular disease and carotid plaques, and also had higher CIMT and PWV, indicating more advanced arterial ageing and vascular damage.

The LDLc had an important heritability with more than $50 \%$ of the variance explained by additive genetic effects, however less than $4 \%$ of the variance resulted from common environmental effects, that may support the notion that lifestyle intervention has little impact on the LDLC levels or that we may have missed to take into account some other shared environmental factors. Moreover, in the GWAS analysis, SNPs located on the LDLR gene presented a strong association with the plasmatic LDLc levels. These findings of a main genetic origin reinforce the need for an early identification and treatment of individuals with $\mathrm{SH}$. The prevalence of polygenic forms of $\mathrm{SH}$ in the general

SUPPLEMENTAL TABLE 4. Association between SNP from the 3 gene candidates and the LDLc levels when excluding subjects without fasting blood sample

\begin{tabular}{|c|c|c|c|c|c|c|c|c|c|c|}
\hline Gene & ID & Chr. & Position & $\mathrm{A} 1$ & $A 2$ & Freq. A2 & Beta & SD & P-value & $\mathrm{PBH}$ \\
\hline \multirow[t]{4}{*}{ LDLR } & rs55997232 & 19 & 11188117 & $\mathrm{~T}$ & $C$ & 0.866 & 0.093 & 0.019 & $8.62 \mathrm{E}-07$ & $2.41 \mathrm{E}-05$ \\
\hline & rs17242395 & 19 & 11206969 & $A$ & G & 0.870 & 0.089 & 0.019 & 2.67E-06 & 3.74E-05 \\
\hline & rs11668477 & 19 & 11195030 & G & A & 0.783 & 0.063 & 0.016 & 4.94E-05 & 4.57E-04 \\
\hline & rs1010679 & 19 & 11207102 & $\mathrm{C}$ & $\mathrm{T}$ & 0.778 & 0.061 & 0.015 & $6.52 \mathrm{E}-05$ & 4.57E-04 \\
\hline \multirow[t]{5}{*}{ PCSK9 } & rs540796 & 1 & 55524197 & A & G & 0.834 & 0.051 & 0.017 & 0.002 & 0.061 \\
\hline & rs505151 & 1 & 55529187 & G & $A$ & 0.968 & -0.089 & 0.035 & 0.011 & 0.151 \\
\hline & rs11591147 & 1 & 55505647 & $\mathrm{~T}$ & G & 0.984 & 0.103 & 0.049 & 0.035 & 0.202 \\
\hline & rs2479394 & 1 & 55486064 & G & A & 0.708 & -0.028 & 0.014 & 0.036 & 0.202 \\
\hline & rs7552841 & 1 & 55518752 & $\mathrm{~T}$ & C & 0.610 & -0.026 & 0.013 & 0.041 & 0.202 \\
\hline \multirow[t]{11}{*}{$A P O B$} & rs1367117 & 2 & 21263900 & A & G & 0.691 & -0.049 & 0.014 & 0.0004 & 0.022 \\
\hline & rs6548010 & 2 & 21277922 & G & A & 0.684 & -0.045 & 0.014 & 0.001 & 0.025 \\
\hline & rs6754295 & 2 & 21206183 & G & $\mathrm{T}$ & 0.756 & 0.046 & 0.015 & 0.002 & 0.032 \\
\hline & rs481069 & 2 & 21281856 & G & $A$ & 0.839 & 0.053 & 0.018 & 0.002 & 0.032 \\
\hline & rs515135 & 2 & 21286057 & $\mathrm{~T}$ & C & 0.790 & 0.046 & 0.016 & 0.004 & 0.040 \\
\hline & rs61743299 & 2 & 21225597 & $\mathrm{~T}$ & A & 0.999 & -0.521 & 0.186 & 0.005 & 0.044 \\
\hline & rs1801695 & 2 & 21224853 & $\mathrm{~T}$ & $C$ & 0.967 & 0.099 & 0.037 & 0.007 & 0.052 \\
\hline & rs1042034 & 2 & 21225281 & $C$ & $\mathrm{~T}$ & 0.781 & 0.040 & 0.016 & 0.010 & 0.064 \\
\hline & rs1042023 & 2 & 21229446 & $\mathrm{C}$ & G & 0.982 & -0.101 & 0.048 & 0.035 & 0.209 \\
\hline & rs12720796 & 2 & 21261998 & $C$ & A & 0.979 & -0.089 & 0.044 & 0.042 & 0.213 \\
\hline & rs13392272 & 2 & 21217490 & $\mathrm{~T}$ & $C$ & 0.551 & -0.026 & 0.013 & 0.044 & 0.213 \\
\hline
\end{tabular}

Legend: LDLc, low-density lipoprotein cholesterol; Chr., chromosome; A1, allele 1; A2, allele 2; beta, effect per A2 under additive genetic model; SD, standard deviation; $\mathrm{BH}$, Benjamini-Hochberg corrected $\mathrm{p}$-value. Sex and age are used as covariates 
SUPPLEMENTAL TABLE 5. Genetic comparisons between individuals taking Statins or not for the 3 candidate genes associated with $\mathrm{SH}$ occurrence using association tests for binary variables

\begin{tabular}{lcc}
\hline & P value & P BH \\
\hline PCSK9 & & \\
Rs28385710 & 0.005 & 0.16 \\
Rs72646509 & 0.02 & 0.38 \\
Rs634272 & 0.05 & 0.48 \\
LDLR & & \\
Rs17242395 & 0.002 & 0.06 \\
Rs55997232 & 0.004 & 0.06 \\
APOB & & \\
\hline Rs61742247 & 0.001 & 0.05 \\
Rs13392272 & 0.003 & 0.05 \\
\hline Rs515135 & 0.004 & 0.05 \\
\hline Rs12713956 & 0.004 & 0.05 \\
\hline
\end{tabular}

Sex and age are used as covariates

For this table only, the 213 subjects that were using statins have been included in the dataset.

population is high, easy to identify, and the cardiovascular damage is potentially preventable.

In our cohort the prevalence of participants with $\mathrm{SH}$ was higher than the prevalence usually described in the literature ${ }^{4,5}$. It should be noted that if these individuals had not been included in our cohort they would otherwise have not be identified. These findings are reflective of the"realworld" where a low proportion of people are diagnosed and treated. Supporting our findings, the prevalence of LDLc $\geq 190 \mathrm{mg} / \mathrm{dL}$ among American adults free of coronary artery disease was also $7 \%$, and they had a multiple fold higher risk of cardiovascular events ${ }^{16}$. Moreover, a familial hypercholesterolemia monogenic mutation identified by gene sequencing was rare $(<2 \%$ among those with a LDLc $\geq 190 \mathrm{mg} / \mathrm{dL})^{16}$. To date, there is no gold standard for the clinical diagnosis of $\mathrm{SH}$. Nonetheless, the first step is to assess the cholesterol levels and to perform a thorough clinical examination looking for features of hypercholesterolemia (e.g., xanthomas, xanthelasmas) and premature cardiovascular disease (e.g., angina pectoris, intermittent claudication, erectile dysfunction) ${ }^{17}$. Although these features may be useful in the case of severe autosomal dominant hypercholesterolemia, they are of little utility for the great majority of people with polygenic forms of hypercholesterolemia. In our cohort we did not systematically evaluate the presence of xanthomas or xanthelasmas, and the proportion of patients with any of myocardial infarction, stroke, or peripheral artery disease was low $(\leq 10 \%)$ is not different between people with $\mathrm{SH}$ or not. On the other hand, a simple LDLc measurement could identify patients with carotid plaques, signals of premature vascular ageing (as supported by higher PWV and CIMT), and family history of premature cardiovascular disease ${ }^{18,19}$. Given the important hereditary component of LDLc, this simple and inexpensive laboratorial measurement (i.e. Blood measurement of LDLc) should be used for screening of $\mathrm{SH}$. As supported by our findings, many of these patients will not present an identifiable gene mutation, but rather present polygenic profiles that will make them more prone to have elevated LDLC.

We found that variants located on $L D L R$ gene (rs55997232, rs17242395, rs1010679, and rs11668477) were those with stronger association with LDLc levels in our cohort. However, none of these 4 SNPs have been identified in previous studies. Variants located on the APOB gene (rs1367117, rs6548010, rs6754295, rs481069, rs61743299 and rs515135) presented lower association with LDLc. The variant rs1367117 had already been previously associated with higher concentrations of $\operatorname{LDLC}^{20}$. Furthermore, some SNPs located on PCSK9 gene, which did not reach the statistically significant threshold in our study, are known for their associations with LDLc ${ }^{21-25}$.

Despite the fact that our findings are not in total concordance with those already reported in other cohorts and populations of different ethnic backgrounds ${ }^{8,14,26}$, the density of our genotyping is not sufficient to find a mutation of one of the 3 genes commonly implicated in familial form; if we consider a $0.5 \%$ or lower prevalence of hypercholesteromemia-associated variants, it is very plausible that we had found none among our 102 patients more likely to have any form of hypercholesterolemia. In this regard, the heritability of LDLc was important, highlighting the need for an early detection and treatment of hypercholesterolemia, thus limiting the lifetime cumulative exposure to elevated LDLc ${ }^{16,27}$. For limiting the exposure to excessive LDLc levels in this high-risk population, and beyond lifestyle changes, an early initiation of statins is required (at least in the great majority of patients who have any form of $\mathrm{SH}$ ). Early (during childhood and adolescence) statin initiation with the goal of lowering LDLc below $100 \mathrm{mg} / \mathrm{dL}$ may delay the progression of vascular damage and reduce the incidence of cardiovascular events ${ }^{19,28,29}$. In addition to statins, PCSK9 inhibitors and Ezetimibe may be considered in people unable to tolerate intensive statin therapy or in whom statins are ineffective to lower LDLc to the desired target. Using the STANISLAS cohort, we have previously shown that the circulating PCSK9 levels and 
the missense mutation coding the SNP rs562556 were associated with the advent of carotid arterial plaques ${ }^{30}$. This SNP was not associated with the LDLc levels in the present report. Whenever required other lipid-lowering strategies can also be tried (e.g., ezetimibe and bile acid sequestrants) ${ }^{14}$.

Our findings add to the literature that milder polygenic forms of SH may be much more prevalent that initially thought. An important proportion of people carrying these $\mathrm{SH}$ forms develop premature vascular damage and may have increased risk of cardiovascular events. Both the diagnosis and effective treatment are relatively easy to achieve (e.g., family history and LDLc measurement), but need to be performed early in life to avoid lifetime exposure to high LDLc levels and reduce the incidence of cardiovascular events.

\section{LIMITATIONS}

This study has several limitations. First, this is an observational study and no causality can be established. Second, our sample size might be underpowered to detect genetic mutations and monogenic alterations and the STANISLAS cohort had participants mostly from the Lorraine region of France. Therefore, the low incidence of monogenic familial hypercholesterolemia found herein cannot be generalized to other populations. Third, this is a cohort of mostly healthy people and the impact of LDLc in major adverse cardiovascular events cannot be determined. Fourth, family history was reported by the participants and not confirmed using medical records. Fifth, the presence of xanthomas and xanthelasmas was not systematically assessed. Sixth, we used age and LDLC for $\mathrm{SH}$ classification. These criteria are sensitive but less specific i.e., they may incorporate people with sporadic forms of hypercholesterolemia; notwithstanding, these forms likely have an important hereditary component (as here described) and more attention should be payed to them

\section{CONCLUSIONS}

In a generally healthy populational cohort not taking statins, the proportion of participants with SH was nearly $7 \%$. These participants had much higher LDL and total cholesterol levels, family history of cardiovascular disease, and premature vascular damage including carotid plaques. LDLc had an important component of heritability with little environmental effect. SNPs linked to the $L D L R$ gene presented a strong association with the blood LDLc levels. These findings reinforce the need for an early identification and treatment of individuals with possible $\mathrm{FH}$ as identified by elevated LDLc levels.

\section{Acknowledgements}

We acknowledge Robert Olaso and his lab "Production Platforms in Human Genomics" at CNRGH for genotyping data production. Anne Boland at CNRGH for management of the genotyping study. This biomarker study was funded by the French National Research Agency Fighting Heart Failure (ANR-15-RHU-0004) and FEDER Lorraine, and all coauthors are supported by the French PIA project "Lorraine Université d'Excellence" GEENAGE (ANR-15-IDEX-04-LUE) programmes, and the Contrat de Plan Etat Région Lorraine and FEDER IT2MP.

We are highly grateful to the Vandoeuvre-Lès Nancy Centre de Médecine Préventive staff, and to Dr Sophie Visvikis-Siest (Inserm U1122) who managed the STANISLAS Cohort for first three visits. The authors deeply thank the Staff of the Clinical Investigation Center and other personnel involved in the Stanislas Cohort management: Biostatisticians: Fay R, Lamiral Z, Machu JL. Computer scientists: Boucenna N, Gallina-Muller C, Maclot PL, Sas T. Co-investigators: Chau K, Di Patrizio P, Dobre D, Gonthier D, Huttin O, Malingrey L, Mauffrey V, Olivier A, Poyeton T, Steyer E, Watfa G. Datamanagers: Cimon P, Eby E, Merckle L. Data entryoperators: Batsh M, Blanger O, Bottelin C, Haskour N, Jacquet V, Przybylski MC, Saribekyan $Y$, Thomas $H$, Vallee M. Echocardiographists, echographists: Ben Sassi M, Cario S, Camara Y, Coiro S, Frikha Z, Kearney-Schwartz A, Selton-Suty C, Watfa G. Imaging engineer: Bozec E. Laboratory Engineer Nuee-Capiaumont J and Technicians: Fruminet J, Kuntz M, Ravey J, Rousseau E, Tachet C. Project manager:BoualiS, Hertz C. Quality engineer: LepageX. Registered Nurses: Giansily M, Poinsignon L, Robin N, Schmartz M, Senn M, Micor-Patrignani E, Toutlemonde M. Hospital technician: Fleurot MT. Resident doctors: Alvarez-Vasquez R, Amiot M, Angotti M, Babel E, Balland M, Bannay A, Basselin P, Benoit P, Bercand J, Bouazzi $M$, Boubel E, Boucherab-Brik N, Boyer F, Champagne C, Chenna SA, Clochey J, Czolnowski D, Dal-Pozzolo J, Desse L, Donetti B, Dugelay G, Friang C, Galante M, Garel M, Gellenoncourt A, Guillin A, Hariton ML, Hinsiger M, Haudiquet E, Hubert JM, Hurtaud A, Jabbour J, Jeckel S, Kecha A, Kelche G, Kieffert C, Laurie 're E, Legay $M$, Mansuy A, Millet-Muresan O, Meyer N, Mourton E, Naude 'AL, Pikus AC, Poucher $M$, Prot M, Quartino A, Saintot $M$, Schiavi A, Schumman $R$, Serot $M$, Sert $C$, Siboescu $R$, Terrier-de-la-Chaise $S$, Thiesse A, Thietry L, Vanesson M, Viellard M. Secretaries: De Amorin E, Villemain C, Ziegler N. Study Coordinators: Dauchy E, Laurent $S$, and all persons not listed above who helped to the funding, initiation, accrual, management and analysis of the fourth visit of the STANISLAS cohort. They also thank the CRB Lorrain of the Nancy CHRU for management of the biobank. Steering committee: Pierre Mutzenhardt, Mehdy Siaghy, Patrick Lacolley, Marie-Ange Luc, Pierre Yves Marie, Jean Michel Vignaud. Advisory members: Sophie Visvikis Siest, F Zannad. Technical committee: Christiane Branlant, Isabelle Behm-Ansmant, JeanMichel Vignaud, Christophe Philippe, Jacques Magdalou, Faiez Zannad, Patrick Rossignol. Scientific committee: Laurence Tiret, Denis Wahl, Athanase Benetos, Javier Diez, Maurizio Ferrari, 
Jean Louis Gueant, Georges Dedoussis, François Alla, Franc, ois Gueyffier, Pierre-Yves Scarabin, Claire Bonithon Kopp, Xavier Jouven, Jean-Claude Voegel, Jan Staessen.

\section{Funding}

This study was funded by the French National Research Agency Fighting Heart Failure (ANR-15-RHU-0004) and FEDER Lorraine, and all coauthors are supported by the French PIA project "Lorraine Université d'Excellence" GEENAGE (ANR-15IDEX-04-LUE) programs, and the Contrat de Plan Etat Région Lorraine and FEDER IT2MP.

\section{Conflict of Interest}

The authors declare that they have no competing interests

\section{REFERENCES}

1. Singh A, Gupta A, Collins BL, Qamar A, Monda KL, Biery $D$, et al. Familial hypercholesterolemia among young adults with myocardial infarction. J Am Coll Cardiol. 2019 May;73(19):2439-50.

2. Austin MA, Hutter CM, Zimmern RL, Humphries SE. Familial hypercholesterolemia and coronary heart disease: A HuGE association review. Am J Epidemiol. 2004 Sep;160(5):421-9.

3. EAS Familial Hypercholesterolaemia Studies Collaboration (FHSC). Global perspective of familial hypercholesterolaemia: a cross-sectional study from the EAS Familial Hypercholesterolaemia Studies Collaboration (FHSC). Lancet [Internet]. 2021 Sep;S0140-6736(21)01122-3. Doi: 10.1016/S0140-6736(21)01122-3. Epub ahead of print. PMID: 34506743. Available from: https://pubmed.ncbi. nlm.nih.gov/34506743/

4. Nordestgaard BG, Chapman MJ, Humphries SE, Ginsberg HN, Masana L, Descamps OS, et al. Familial hypercholesterolaemia is underdiagnosed and undertreated in the general population: guidance for clinicians to prevent coronary heart disease: Consensus statement of the European Atherosclerosis Society. Eur Heart J. 2013 Dec;34 (45):3478-90.

5. Akioyamen LE, Genest J, Shan SD, Reel RL, Albaum JM, Chu A, et al. Estimating the prevalence of heterozygous familial hypercholesterolaemia: a systematic review and meta-analysis. BMJ Open. 2017 Sep;7(9):e016461.

6. Benn M, Watts GF, Tybjærg-Hansen A, Nordestgaard BG. Mutations causative of familial hypercholesterolaemia: screening of 98098 individuals from the Copenhagen General Population Study estimated a prevalence of 1 in 217. Eur Heart J. 2016 May;37(17):1384-94.

7. Trinder M, Li X, DeCastro ML, Cermakova L, Sadananda $S$, Jackson LM, et al. Risk of premature atherosclerotic disease in patients with monogenic versus polygenic familial hypercholesterolemia. J Am Coll Cardiol, 2019 Jul;74 (4):512-22.

8. Trinder M, Francis GA, Brunham LR. Association of monogenic vs polygenic hypercholesterolemia with risk of atherosclerotic cardiovascular disease. JAMA Cardiol 2020 Feb;5(4):390-9.
9. Ferreira JP, Girerd N, Bozec E, Merckle L, Pizard A, Bouali $S$, et al. Cohort Profile: Rationale and design of the fourth visit of the STANISLAS cohort: A familial longitudinal population-based cohort from the Nancy region of France. Int J Epidemiol 2018 Apr;47(2):395-395j.

10. Frikha Z, Girerd N, Huttin O, Courand PY, Bozec E, Olivier A, et al. Reproducibility in echocardiographic assessment of diastolic function in a population based study (the STANISLAS Cohort study). PLoS One [Internet]. 2015 Apr;10(4):e0122336. Available from: https://www.ncbi. nlm.nih.gov/pmc/articles/PMC4390157/

11. Wagner S, Lioret S, Girerd N, Duarte K, Lamiral Z, Bozec $E$, et al. Association of dietary patterns derived using reduced-rank regression with subclinical cardiovascular damage according to generation and sex in the STANISLAS Cohort. J Am Heart Assoc. 2020 Apr;9(7):e013836.

12. Ferreira JP, Girerd N, Bozec E, Machu JL, Boivin JM, London GM, et al. Intima-media thickness is linearly and continuously associated with systolic blood pressure in a population-based cohort (STANISLAS Cohort Study). J Am Heart Assoc. 2016 Jun;5(6):e003529.

13. Cuchel M, Bruckert E, Ginsberg HN, Raal FJ, Santos RD, Hegele RA, et al. Homozygous familial hypercholesterolaemia: New insights and guidance for clinicians to improve detection and clinical management. A position paper from the Consensus Panel on Familial Hypercholesterolaemia of the European Atherosclerosis Society. Eur Heart J. 2014 Aug;35(32):2146-57

14. McGowan MP, Hosseini Dehkordi SH, Moriarty PM, Duell PB. Diagnosis and treatment of heterozygous familial hypercholesterolemia. J Am Heart Assoc. 2019 Dec;8(24):e013225.

15. Xhaard C, Dandine-Roulland C, Villemereuil P, Floch EL, Bacq-Daian D, Machu JL, et al. Heritability of a resting heart rate in a 20-year follow-up family cohort with GWAS data: Insights from the STANISLAS cohort. Eur J Prev Cardiol [Internet]. 2019 Dec;2047487319890763. Online ahead of print. Available from: https://pubmed. ncbi.nlm.nih.gov/31791143/

16. Khera AV, Won HH, Peloso GM, Lawson KS, BartzTM, Deng $X$, et al. Diagnostic yield and clinical utility of sequencing familial hypercholesterolemia genes in patients with severe hypercholesterolemia. J Am Coll Cardiol. 2016 Jun;67(22):2578-89.

17. Goldberg AC, Hopkins PN, Toth PP, Ballantyne CM, Rader DJ, Robinson JG, et al. Familial hypercholesterolemia: Screening, diagnosis and management of pediatric and adult patients: Clinical guidance from the National Lipid Association Expert Panel on Familial Hypercholesterolemia. J Clin Lipidol. 2011 Jun;5(3 Suppl):S1-8.

18. Wiegman A, Hutten BA, de Groot E, Rodenburg J, Bakker $H D$, Büller HR, et al. Efficacy and safety of statin therapy in children with familial hypercholesterolemia: A randomized controlled trial. JAMA. 2004 Jul;292(3):331-7.

19 Kusters DM, Avis HJ, de Groot E, Wijburg FA, Kastelein JJ, Wiegman A, et al. Ten-year follow-up after initiation of statin therapy in children with familial hypercholesterolemia. JAMA. 2014 Sep;312(10):1055-7.

20. Costanza MC, Beer-Borst S, James RW, Gaspoz JM, Morabia A. Consistency between cross-sectional and longitudi- 
nal SNP: blood lipid associations. Eur J Epidemiol. 2012 Feb;27(2):131-8.

21. Hubacek JA, Adamkova V, Lanska V, Dlouha D. Polygenic hypercholesterolemia: Examples of GWAS results and their replication in the Czech-Slavonic population. Physiological research. 2017 Apr;66(Suppl 1):S101-11.

22. Karami F, Salahshourifar I, Houshmand M. The Study of rs693 and rs515135 in APOB in people with familial hypercholestrolemia. Cell J. 2019 Spring;21(1):86-91.

23. Benn M, Tybjaerg-Hansen A, Nordestgaard BG. Low LDL cholesterol by PCSK9 variation reduces cardiovascular mortality. J Am Coll Cardiol. 2019 Jun;73(24):3102-14.

24. Rojas C, Ramírez H, Salazar LA, Kalergis AM, Gálvez AS, Escobar-Vera J. Characterization of LDLR rs5925 and PCSK9 rs505151 genetic variants frequencies in healthy subjects from northern Chile: Influence on plasma lipid levels. J Clin Lab Anal. 2019 Nov;33(9):e23001.

25. Guo Q, Si Y, Su M, Fan M, Lin J, Memon NH, et al. PCSK9 rs7552841 is associated with plasma lipids profiles in female Chinese adolescents without posttraumatic stress disorder. Biosci Trends. 2017 Nov; 11(5):542-9.

26. Hu P, Dharmayat KI, Stevens CAT, Sharabiani MTA,
Jones RS, Watts GF, et al. Prevalence of familial hypercholesterolemia among the general population and patients with atherosclerotic cardiovascular disease: A Systematic Review and Meta-Analysis. Circulation. 2020 Jun;141(22):1742-59.

27. Sharifi M, Higginson E, Bos S, Gallivan A, Harvey D, Li KW, et al. Greater preclinical atherosclerosis in treated monogenic familial hypercholesterolemia vs. polygenic hypercholesterolemia. Atherosclerosis. 2017 Aug;263:405-11.

28. Versmissen J, Oosterveer DM, Yazdanpanah M, Defesche JC, Basart DC, Liem AH, et al. Efficacy of statins in familial hypercholesterolaemia: A long term cohort study. BMJ. 2008 Nov;337:a2423.

29. Luirink IK, Wiegman A, Kusters DM, Hof MH, Groothoff JW, de Groot E, et al. 20-Year Follow-up of statins in children with familial hypercholesterolemia. N Engl J Med. 2019 Oct;381(16):1547-56.

30. Ferreira JP, Xhaard C, Lamiral Z, Borges-Canha M, Neves JS, Dandine-Roulland C, et al. PCSK9 Protein and rs562556 polymorphism are associated with arterial plaques in healthy middle-aged population: The STANISLAS Cohort. J Am Heart Assoc. 2020 Apr;9(7):e014758. 